\title{
ASPECTOS AMBIENTAIS DECORRENTES DE LAVRA IRREGULAR, MINERAÇÃO JOÃO PESSOA, SOBRADO - PB
}

\author{
ENVIRONMENTAL ASPECTS ARISING FROM JOÃO PESSOA IRREGULAR MINING, \\ SOBRADO - PB
}

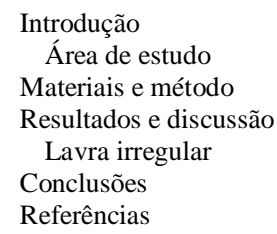

Matheus Diniz Pinto de MORAIS, Gustavo Rodrigues PINTO

Universidade Federal de Pernambuco. Av. Prof. Moraes Rego, 1235 - Cidade Universitária, Recife - PE, E-mails: matheus.dpm@hotmail.com; gustavopinto0@gmail.com

RESUMO - A atividade de mineração tem como peculiaridade o aproveitamento econômico de recursos naturais limitados e não renováveis. Dentre os bens minerais, a produção de agregados para construção civil está diretamente ligada com o desenvolvimento socioeconômico de uma nação, indispensável para obras estruturantes. Em busca de maior competitividade, as pedreiras procuram se instalar próximas aos seus centros consumidores, atrelado sempre aos fatores geológicos, que impõem forte rigidez locacional para empreendimentos mineiros, onde muitas vezes são desenvolvidos em áreas ambientalmente sensíveis, produzindo efeitos ambientais e sociais em todas as fases do empreendimento. $\mathrm{O}$ trabalho em tela teve como objetivo o levantamento dos aspectos ambientais atrelados a prática de atividades de mineração em Áreas de Preservação Permanente (APP's) e fora das prescrições legais. Tomando como elemento norteador a Lei $N^{\circ} 12.651 / 2012$ (novo código florestal) para delimitação das Áreas de Preservação Permanente. De modo a auxiliar na representação das medições realizadas em campo, foi utilizado o geoprocessamento com o intuito de expressar graficamente os elementos ambientais existentes como: rio, área de lavra, área de preservação permanente e suas interferências.

Palavras-chave: Área de Preservação Permanente, Pedreiras, Lavra irregular.

\begin{abstract}
The mining activity has as a peculiarity a good economic use of the limited natural and not renewable resources. Among the mineral goods, the production of supplies for the civil construction is directly connected with the socioeconomic improvement of any nation, indispensable for structural constructions. Searching of a better competitiveness, quarries try to install your operations as near as possible of their consumers centers, attached always to the geological factors, that imposes a strong locational rigidity for mining companies, that are also usually developed in sensible environmentally areas, producing environmental and social effects in all the phases of the enterprise. The work on canvas had the objective of surveying the environmental aspects linked to the practice of mining activities in Permanent Preservation Areas (APP's) and outside the legal prescriptions. Taking as a guiding element the Law No. 12.651/2012 (new forest code) for the delimitation of the Permanent Preservation Areas. In order to assists the representation of the landscape, geoprocessing was used to graphically express the existing environmental elements such as river, mining area, permanent preservation area and their interference.
\end{abstract}

Keywords: Permanent Preservation Area, Quarries, Irregular Mining.

\section{INTRODUÇÃO}

Evidências mostram que a mineração, em seu modo mais primário, surgiu na era Paleolítica, há mais de 450 mil anos. Demonstrando o homem um interesse pelos constituintes da crosta terrestre, seja para fins ornamentais como por exemplo as predas preciosas ou para o aproveitamento de alguma característica físicoquímica. Considerada a segunda atividade industrial mais antiga da nossa história, perdendo apenas para agricultura, tendo sua evolução posteriormente a idade da Pedra (antes de 4000 a.C.) (Curi, 2014).

A relação do homem com a mineração é tão estreita que foi correlacionado o período da Idade do Homem com à evolução no tempo dos usos dos materiais geológicos. Dado início na Idade da Pedra e seguindo sucessivamente por Idade do Cobre, Bronze, Ferro, Carvão, Aço e Petróleo e Urânio (Curi, 2017).

A atividade de mineração tem como peculiaridade o aproveitamento econômico de recursos naturais limitados e não renováveis, objetivando a maximização do valor atual líquido dos benefícios monetários futuros, durante a vida útil do empreendimento. O referido aproveitamento é antecedido de estudo de viabilidade de lavra, sendo um conjunto de aspetos considerados, dentre eles podendo ser citados os aspectos econômicos, legais, tecnológicos, geológicos e ambientais (Curi, 2014). 
Dentre os bens minerais, a produção de agregados para construção civil está diretamente ligada com o desenvolvimento socioeconômico de uma nação. Indispensável para obras estruturantes e edificação sendo utilizados no concreto e argamassa de cimento Portland, concreto asfáltico, lastro ferroviário, aterros, proteção de taludes, filtros, etc. (Luz, 2012).

Em busca de maior competitividade, as pedreiras procuram se instalar próximas aos seus centros consumidores, atrelado sempre aos fatores geológicos, que impõem forte rigidez locacional para empreendimentos mineiros, onde muitas vezes são desenvolvidos em áreas ambientalmente sensíveis, produzindo efeitos ambientais e sociais em todas as fases do empreendimento (Bacci, 2006).

Atualmente, com o crescente consciente relativo da necessidade de empreendimentos respeitarem a sustentabilidade, é exigido na mineração que o início e o fim da exploração mineral estejam associados, devendo ser exigido as medidas e garantias para a recuperação ambiental da área degradada pela mineração e mitigação dos seus impactos, estando a
Recuperação de área degradada, contemplada na CF, art. 225, par. $2^{\circ}$ (Thomé, 2017).

O trabalho tem como objetivo o levantamento dos aspectos ambientais decorrentes de lavra irregular, na Mineração João Pessoa localizada na zona rural do município de Sobrado, região do brejo paraibano.

\section{Área de Estudo}

O empreendimento está inserido no município de Sobrado - PB. A sede do município apresenta 82 metros de altitude e dista 41,6 km de João Pessoa - PB. A hidrografia está inserida nos limites da bacia hidrográfica do Rio Paraíba, possuindo como principais tributários o Rio Gurinhém e os riachos Bonito, Anta e Curimataú, todos os cursos de regime intermitente (CPRM, 2005).

O clima é Tropical Semiárido e a vegetação apresenta predominância de Caatinga Hiperxerófila com algumas exceções de Floresta Caducifólia. Geologicamente a área de lavra encontra-se nos domínios do Complexo Cabaceiras constituído de anfibólio, biotita ortognaisses bandados, laminados (Figura 1) (CPRM, 2005).

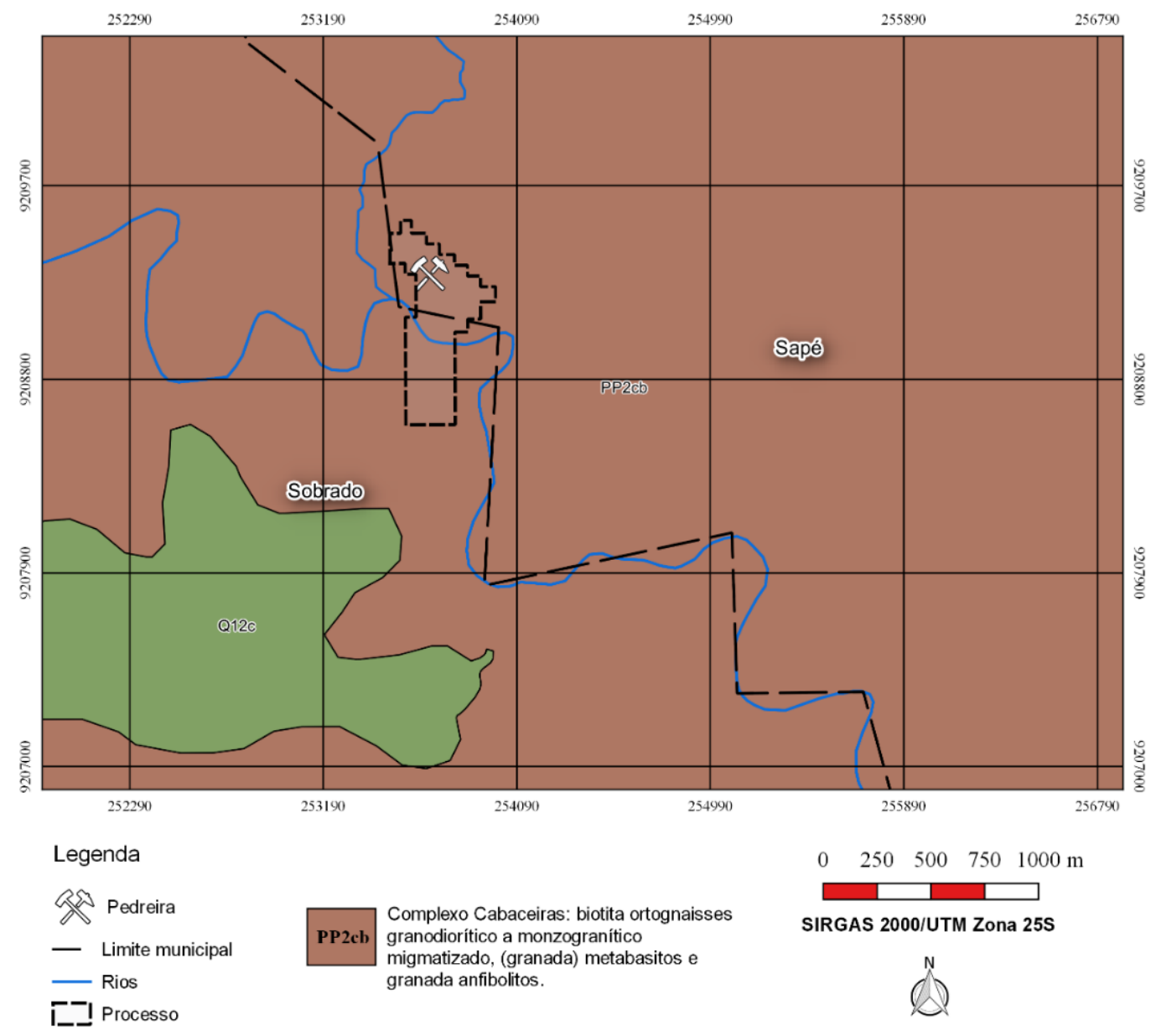

Figura 1 - Mapa Geológico simplificado do Município de Sobrado - PB. 
A unidade descrita possui composição granítica-granodiorítica, apresentando predominância de augen gnaisses (porfiroclastos em forma de olho), as vezes ocorrendo biotita gnaisses bandados, que é o que ocorre no caso estudado, com várias fases de injeções de diques e algumas feições magmáticas como enclaves máficos de composição diorítica (Guimarães et. al., 2017).

O empreendimento em questão está localizado na região do brejo paraibano, no município já discorrido. Teve suas operações iniciadas na década de 80 , passando pela titularidade de diversas empresas. Atualmente o titular detém o licenciamento ambiental pertinente e o registro de licença em seu nome.

A atividade de produção envolve a extração e britagem. Como produtos do beneficiamento são geradas britas de gnaisse dos tamanhos $0,1,2,3,4$ e pó de brita, de modo a suprir a demanda de João
Pessoa e sua região metropolitana.

A lavra é executada a céu aberto, em bancadas de dimensões variáveis (5 a 20 metros de altura) de forma descendente. A cava apresenta uma geometria semicircular, aproximadamente $330 \mathrm{~m}$ x $250 \mathrm{~m}$. As operações unitárias para produção se iniciam com a perfuração e desmonte da rocha, de modo a fragmentar a bancada perfurada e detonada, o minério dentro dos padrões granulométricos para alimentação da usina de beneficiamento são carregados por pá carregadeira e transportados por caminhões até a alimentação do britador primário e basculados, caso contrário é feito o desmonte secundário dos matacões. É uma atividade aparentemente de bastante simplicidade compreendendo a limpeza da área, perfuração, desmonte primário, desmonte secundário, carregamento, transporte, redução granulométrica, classificação granulométrica, estocagem e expedição.

\section{MATERIAIS E MÉTODO}

Os levantamentos dos aspectos ambientais são fundamentais na condução de avaliações ambientais, servindo de ferramenta norteadora dos impactos ambientais ocasionados. Dessa forma, na fase inicial do trabalho foi feita a revisão dos aspectos ambientais ocasionado pelas atividades de lavra, levantamento bibliográfico do município estudado e de conceitos ambientais, em seguida foram realizadas visitas com o intuito de verificar as operações e os aspectos ambientais decorrentes destas.

Para cumprimento do objetivo, foram dirigidas vistorias para observações quanto às atividades e registros fotográficos, conversa com colaboradores da empresa, captura de pontos com GPS de navegação e medições com trena para delimitações de áreas de servidão e elementos ambientais existentes. Além de técnicas de geoprocessamento e conhecimentos empíricos no intuito de mapear e classificar o local das operações.

Com a medição do leito do rio e APP e captura de pontos de interesse, realizada com GPS Garmin
Montana 680, foi feita a delimitação de áreas de servidão e elementos ambientais existentes. Foram empregadas as ferramentas do sensoriamento remoto, através do software QGIS em sua versão 2.18.15 ('Las Palmas'). Utilizando como referência as imagens Google e os pontos captados, foi realizada a classificação da área através do processo de vetorização a mão livre do Rio Gurinhém e da Área consolidada da pedreira. Posteriormente foram gerados dois buffers a partir das margens do Rio, com $50 \mathrm{~m}$ e $100 \mathrm{~m}$, referentes às APP's.

Estes valores foram definidos segundo a legislação vigente dada pela lei $\mathrm{N}^{\circ} 12.651 / 2012$. A área de invasão foi determinada com a sobreposição das camadas relativas a APP e a Área consolidada, calculando a área da região de intersecção entre elas. O processo de mapeamento foi consolidado pelos trabalhos de campo. O mesmo procedimento foi realizado para constatar as áreas lavradas fora do processo da Agência Nacional de Mineração (ANM).

\section{RESULTADOS E DISCUSSÃO}

\section{Lavra Irregular}

A lavra fora das prescrições legais é considerada irregular ou clandestina. No decorrer dos trabalhos de campo foi identificado que ocorreu lavra além do processo ANM, bem como a APP do curso hídrico inserido na área foi violada e lavrada.
Na figura 2, tambor amarelo demarcando um dos vértices da poligonal do processo ANM, após ocorrer lavra fora da mesma. Os vértices do polígono foram demarcados com tambores a fim de evitar a realização da lavra fora dos limites estabelecidos. É possível perceber a invasão em três porções da área, zona norte no entorno do 
ponto de localização - 78'47.56"S - 35¹3'48.37"O (Figura 4), zona oeste no entorno do ponto de localização - 78'55.08"S - 35²13'52.12"O (Figura
5) e zona leste no entorno do ponto de localização - 79'1.91"S - 35²13'42.67"O. A figura 3 destaca as porções mencionadas.

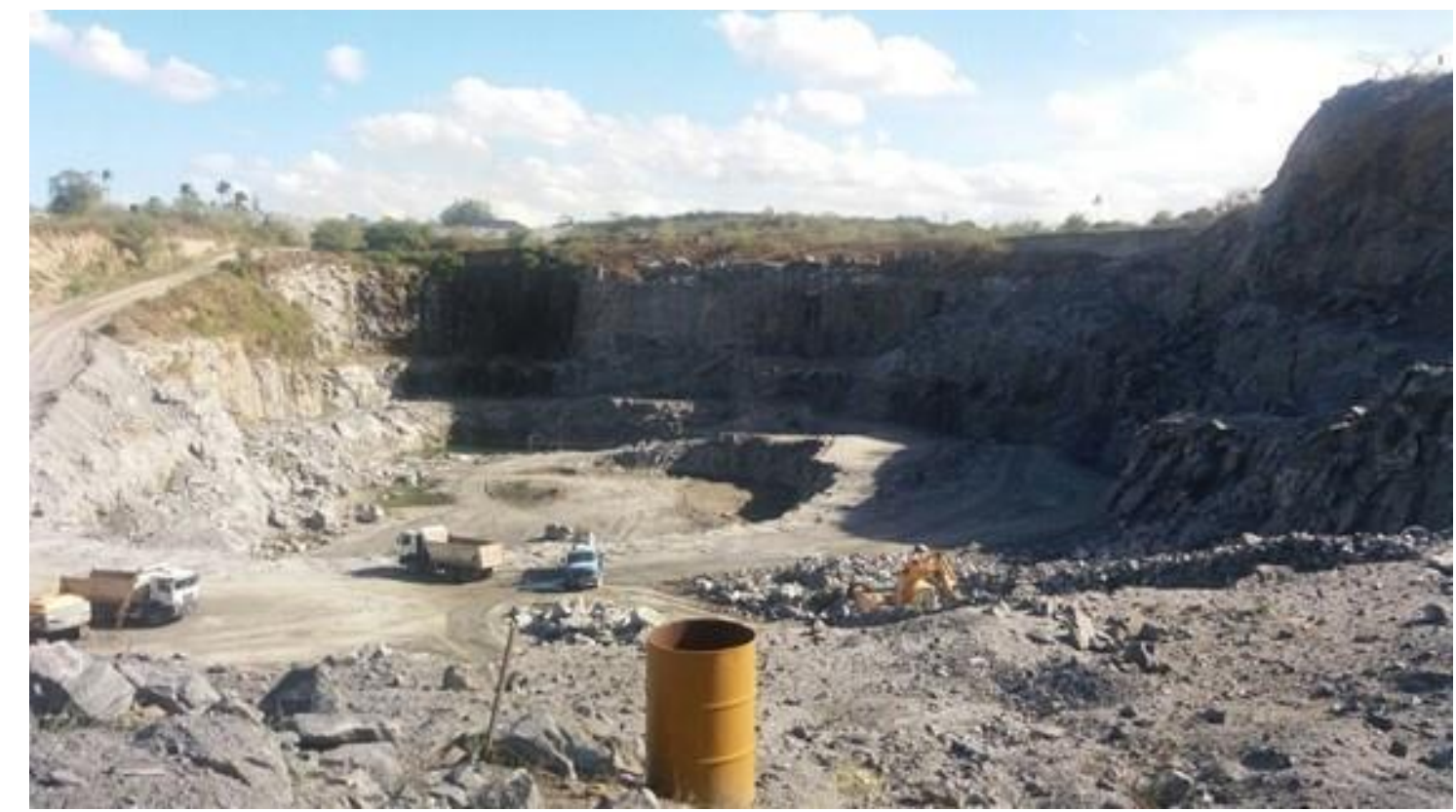

Figura 2 - Demarcação dos vértices da poligonal.



Figura 3 - Porções lavradas fora dos limites do processo. 
Porção norte e oeste da área onde outrora ocorreu lavra ilegal, figura 4 , pode se observar a formação de duas bancadas e o volume considerado que foi lavrado, assim como na figura 5, está sendo apresentada a região oeste que também passou por intervenções sem a devida autorização.

No lado sul da pedreira é possível visualizar a percolação de água constante que ocorre entre as famílias de juntas do maciço, em destaque na figura 6. Ainda nessa região o paredão rochoso apresenta uma coloração diferenciada, mostrando um tom amarronzado dos seus minerais, provavelmente pela alteração dos constituintes ferrosos da rocha, dado que se trata de um ortognaisse.

Durante a vistoria, foi informado por um dos responsáveis da pedreira, que com a cheia do rio, o mesmo transborda e enche a cava. A figura 6 apresenta o rio em destaque na parte superior do maciço. Ainda na porção descrita, ocorreu a lavra de parte da APP do rio, levando a crer que esse fato tenha contribuído para percolação de água entre juntas e desvio de parte da água do rio para dentro da cava. Pelo fluxo de água, número de famílias de juntas, estado de alteração do maciço e regime hídrico do rio, é possível sugerir a baixa segurança geotécnica existente no empreendimento, atentando contra a seguridade dos colaboradores da pedreira.

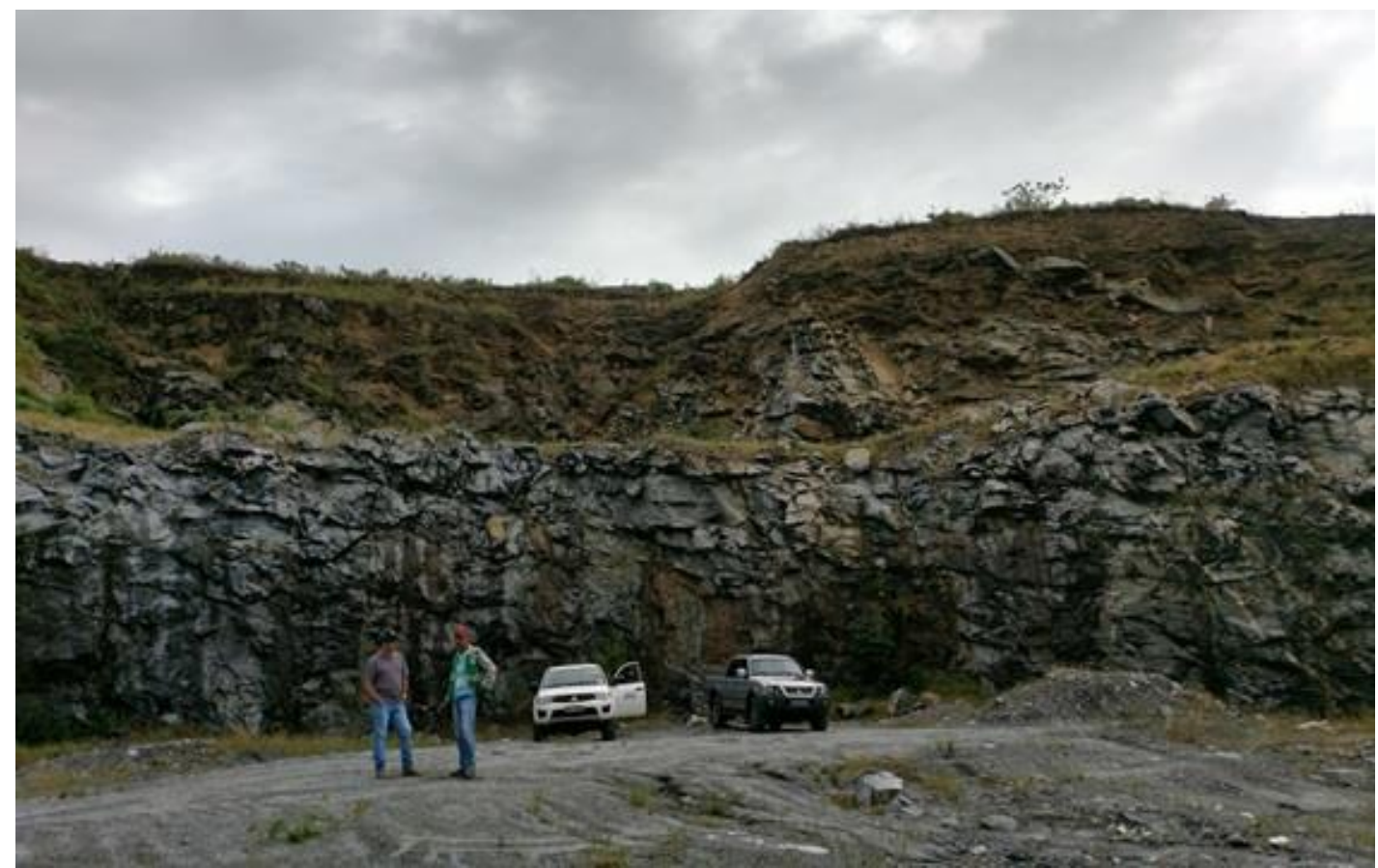

Figura 4 - Região norte lavrada ilegalmente.



Figura 5 - Em destaque a área de lavra não autorizada praticada na porção oeste da cava. 


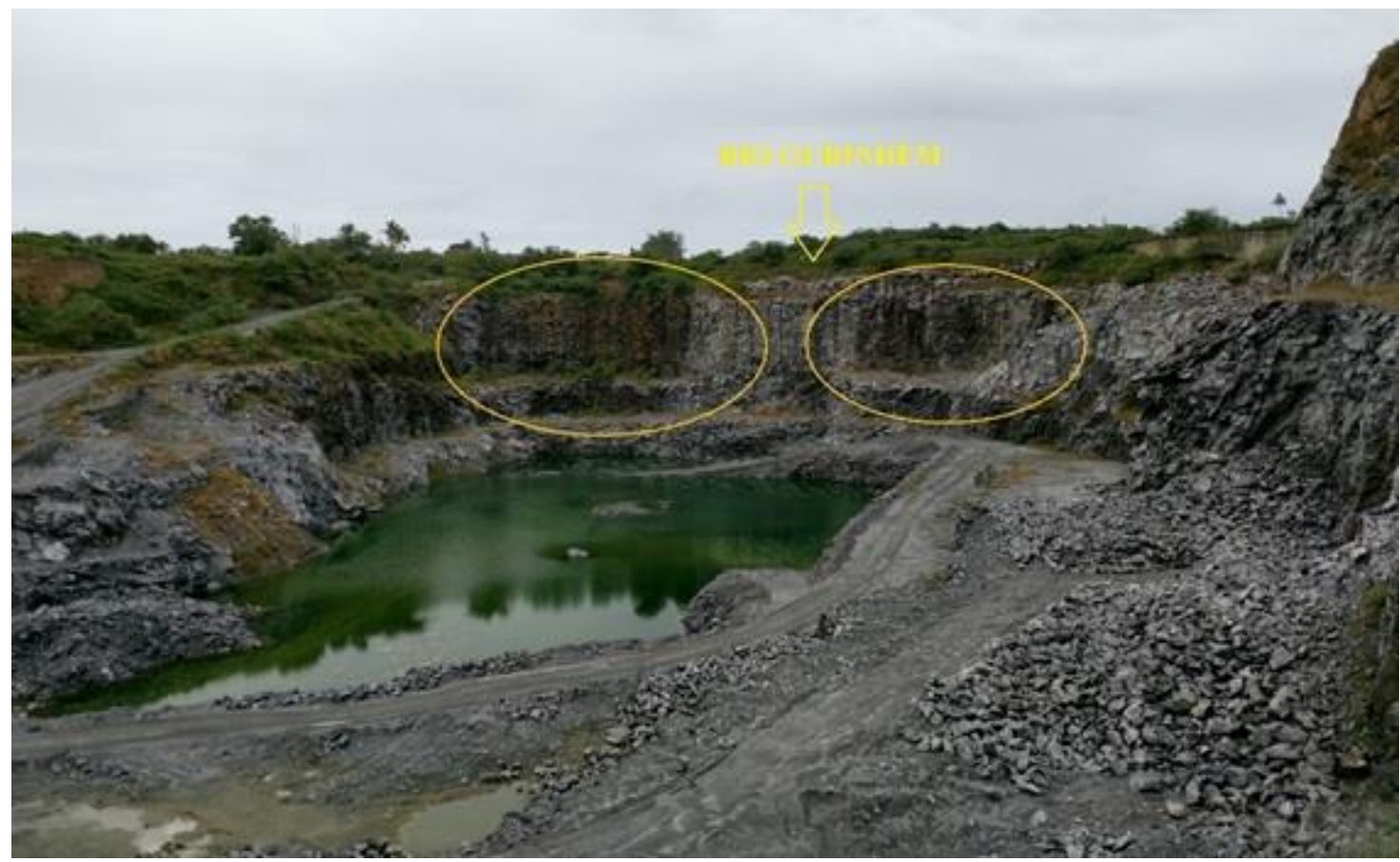

Figura 6 - Visita realizada em período de suspensão da lavra.

Utilizando do sensoriamento remoto e percurso do rio, foi então considerada a Lei $\mathrm{n}^{\circ}$ medição da largura do rio em campo, foi projetada a APP referente ao rio nos pontos margeantes à cava e feita sua interseção com a geometria da mina, para então ser calculada a área de interferência existente entre a APP e a geometria da pedreira, como pode ser observada nas figuras 7,8 e 9 .

Com as delimitações realizadas em campo e auxílio do sensoriamento remoto para esboçar o 12.651/2012 (Novo Código Florestal), estando disposto em seu art. $4^{\circ}$ e demais incisos as consideração de Áreas de Preservação Permanente, ficando a situação em tela atrelada ao inciso I, in verbis: "I - as faixas marginais de qualquer curso d'água natural perene $e$ intermitente, excluídos os efêmeros, desde a borda da calha do leito regular, em largura mínima de (...)".



Figura 7 - Contorno dos elementos em análise. 
Para o trecho analisado do Rio Gurinhém, foram designadas duas larguras distintas para a APP; a primeira de 50 (cinquenta) metros, para as partes que tenham entre 10 (dez) e 50 (cinquenta) metros de largura, e a mais larga com 100 (cem) metros para trechos variando de 50 (cinquenta) a 200 (duzentos) metros de largura, seguindo estritamente a alínea b e c, inciso I, art. $4^{\circ}$ da lei supracitada.
Após a delimitação da APP, rio, área de lavra e depósito (área consolidada), foi feito o preenchimento dos shaps relativos a cada denominação, sendo possível notar a geometria da cava acompanhando o traçado do curso do rio (figura 8), sendo difícil afirmar se o traçado atual do rio é natural ou sofreu modificação pelo empreendimento, visto grande similaridade estre as duas estruturas.

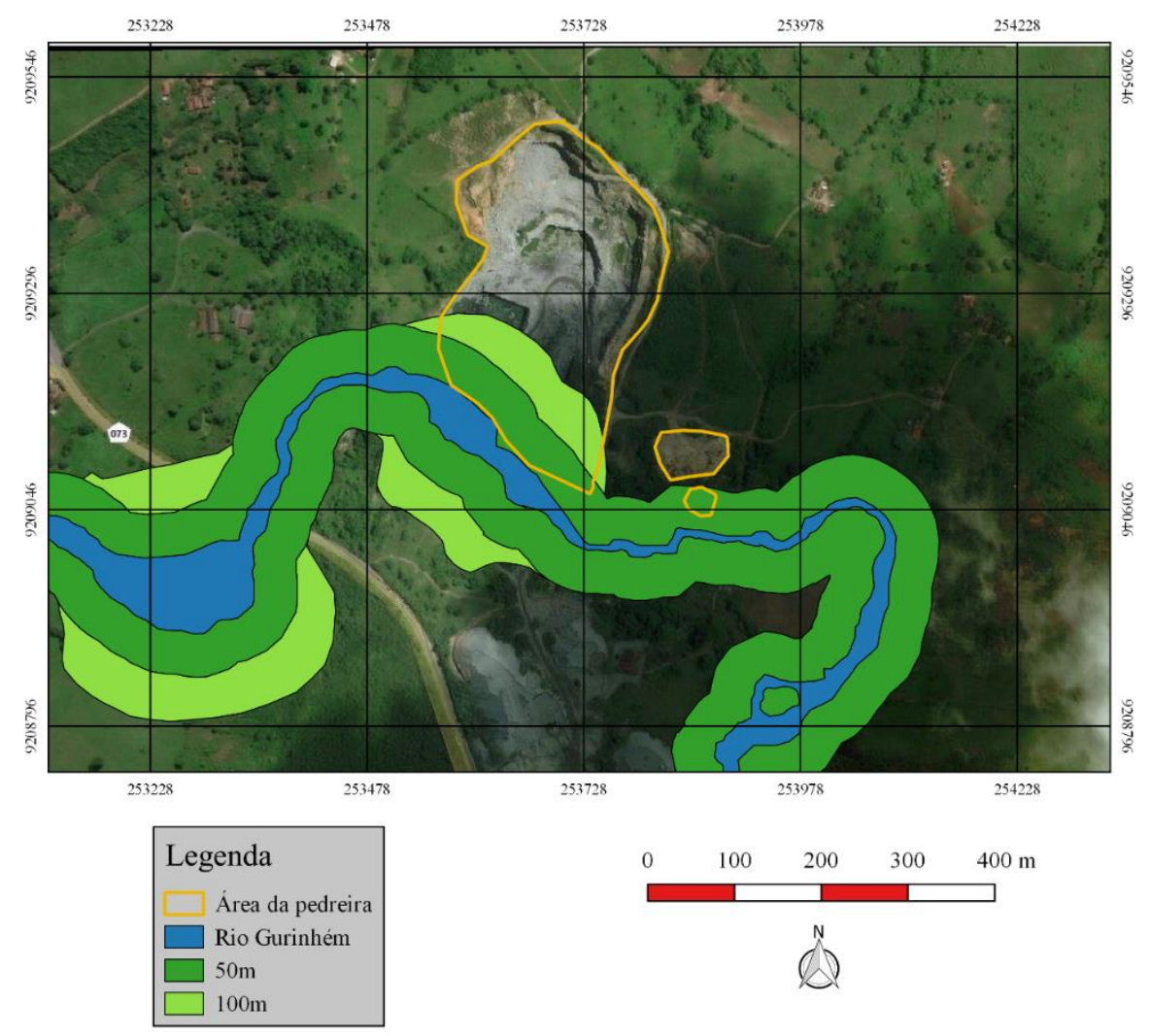

Figura 8 - Intersecção entre a cava da pedreira e a APP.

$\mathrm{Na}$ figura 9 é apresentado novamente os traçados existentes dos elementos ambientais em análise, com suas planimétricas em destaque, enfatizando as interseções entre as áreas consolidadas e as porções ambientalmente sensíveis. Foi mensurada, para área de lavra, um avanço indevido dentro da APP de 2,11 ha (dois hectares e onze ares) e do depósito controlado de estéril, uma área ocupando 0,09 ha (nove ares) dentro da área de preservação.

$\mathrm{Na}$ tabela 1 é listado os aspectos decorrentes das invasões citadas, devendo o responsável arcar com a responsabilidade administrativoambiental por seus atos.

\section{CONCLUSÕES}

Pela importância da mineração, ela tem seu caráter de utilidade pública, sendo fundamental no desenvolvimento de uma nação, servindo como elemento estratégico. É indiscutível os danos ambientais causados pela atividade de mineração, até mesmo por ser uma apropriação privada de um recurso não renovável, danos esses pontuais. No entanto é uma atividade juridicamente lícita e indispensável, pois, até nas sociedades humanas mais primitivas, são encontrados vestígios de que ocorreu atividade mineira. A observação inicial da pesquisa possibilitou detectar uma enorme deficiência na gestão ambiental do empreendimento, atrelado também a ausência de responsáveis técnicos no acompanhamento das atividades.

Nas etapas analisadas, os aspectos ambientais mais frequentes foram: ruído, vibração, emissão de particulados, emissão de gases e consumo de recursos naturais e energéticos. $\mathrm{O}$ gerenciamento dos aspectos ambientais deve ser realizado continuamente, $o$ 
acompanhamento dos processos é fator reconhecimento dos impactos correspondentes, fundamental para controle dos aspectos e podendo então serem mitigados.

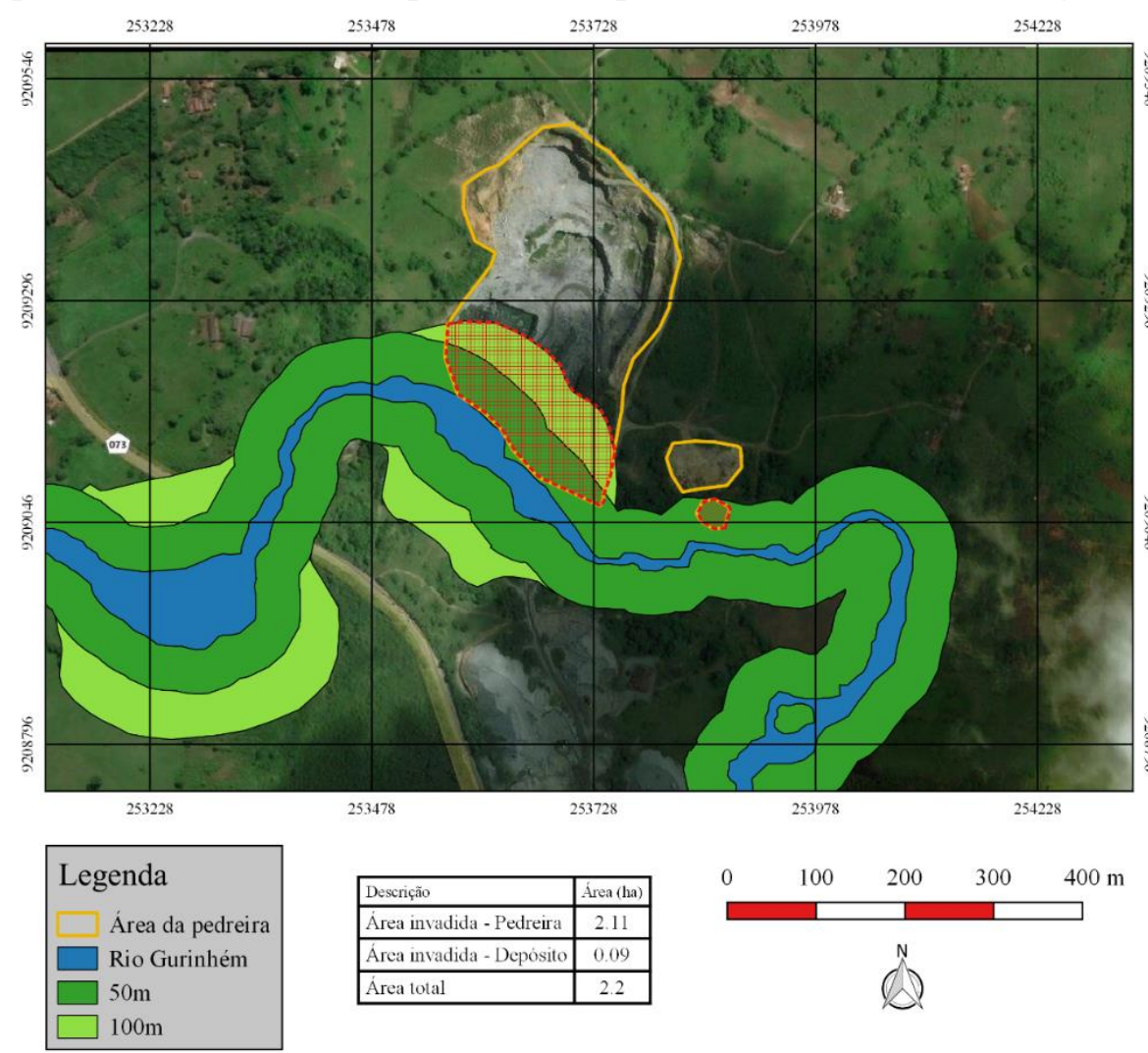

Figura 9 - Intersecção demonstrando uma invasão de 2.20 ha.

Tabela 1 - Aspectos decorrentes de lavra ilegal (modificado de Sánchez, 2013).

\begin{tabular}{c|l}
\hline \multicolumn{1}{c|}{ Atividades } & \multicolumn{1}{c}{ Aspectos Ambientais } \\
\hline \multirow{3}{*}{ Lavra fora da poligonal } & Consumo de recursos ambientais não autorizados \\
& Alteração das Características do solo \\
& Modificação das formas de uso do solo \\
& Alteração da topografia local \\
& Não atendimento da legislação ambiental e mineral \\
& Ruído, Vibração \\
& Emissão de particulados, Emissão de gases \\
\hline \multirow{2}{*}{ Lavra em APP } & Necessidade de intervenção com construção de contenção \\
& Consumo de recurso ambiental \\
& Alteração das Características do solo \\
& Represamento parcial de cursos d'água \\
& Alteração da topografia local \\
& Modificação das formas de uso do solo \\
& Perda da cobertura vegetal \\
& Alteração da rede hidrográfica \\
& Alteração do nível freático \\
& Não atendimento a legislação mineral e ambiental em vigor \\
& Ruído, Vibração \\
& Emissão de particulados, Emissão de gases \\
\hline
\end{tabular}

Modificações irreversíveis foram ocasionadas. A principal que pode ser citada é o desvio do curso do rio, que agora tende a seguir para dentro da cava da pedreira, o que levou a uma intervenção da APP pela construção de um muro de contenção do fluxo do rio, tal fato cria um risco geotécnico na mina, que é agravado em épocas de cheias do rio.
Além disso, é de extrema necessidade o cercamento e revitalização da APP, de modo a evitar o trânsito de animais e pessoas, com a finalidade de auxílio na sua recuperação.

Com base nas condições atuais do empreendimento, onde é visto uma extração em estado bem avançado e nenhuma medida de compensação sendo tomada, no longo 
período que ocorre reabilitação de uma área, nas diferentes superfícies com características distintas para reabilitação (taludes de corte, taludes de aterro, APP e etc.), $\mathrm{Na}$ complexidade da recuperação de uma área minerada (testes de ordem física, fertilidade e de ordem biológica), é extremamente crucial o início da atividade de recuperação da área afetada, como forma de mitigar parte do dano constatado.

\section{REFERÊNCIAS}

BACCI, D.L.C; LANDIM, P.M.B; ESTON, S.M. Aspectos e impactos ambientais de pedreira em área urbana. REM: Revista Escola de Minas, Ouro Preto, v. 59, n. 1, p: 47-54, 2006.

BRASIL. Congresso Nacional. Lei $\mathrm{n}^{\circ} 12.651,25$ de maio de 2012. Dispõe sobre a proteção da vegetação nativa; altera as Leis nos 6.938, de 31 de agosto de 1981, 9.393, de 19 de dezembro de 1996, e 11.428, de 22 de dezembro de 2006; revoga as Leis $\mathrm{n}^{\mathrm{os}} \mathbf{4 . 7 7 1}$, de 15 de setembro de 1965 , e 7.754 de 14 de abril de 1989, e a Medida Provisória no 2.166-67, de 24 de agosto de 2001; e dá outras providências. Diário Oficial da República Federativa do Brasil, Poder Executivo, Brasília, DF, 25 mai. 2012.

CPRM. Projeto cadastro de fontes de abastecimento por água subterrânea: Diagnóstico do município de Sobrado, estado da Paraíba. Recife: CPRM/PRODEEM, 10 p., 2005.

CURI, A. Lavra de Minas. $1^{a}$ ed. São Paulo: Oficina de Textos, 462 p., 2014.
CURI, A. Minas a Céu Aberto: planejamento de lavra. $1^{\mathrm{a}}$ ed. São Paulo: Oficina de Textos, 223 p., 2017.

GUIMARÃES, I.P.; SCHULZE, S.M.B.B.; FARIAS, D.J.S.; YADAV, R.; ALMEIDA, C.N. Geologia e recursos minerais da Folha Sapé SB.25-Y-C-II Escala 1:100.000. Estado da Paraíba. Recife: CPRM - Serviço Geológico do Brasil, 73 p., 2017.

LUZ, A.B. \& ALMEIDA L.M. Manual de Agregados para construção civil. $2^{a}$ ed. Rio de Janeiro: CETEM/MCTI, 452 p., 2012.

SÁNCHEZ, L.E. Avaliação de impacto ambiental: conceitos e métodos. $2^{\mathrm{a}}$ ed. São Paulo: Oficina de Textos, 583 p., 2013.

THOMÉ, R. Mineração e Meio Ambiente: Análise jurídica interdisciplinar. $1^{\mathrm{a}}$ ed. Rio de Janeiro: Lumen Juris, 332p., 2017.

Submetido em 30 de junho de 2018 Aceito em 3 de maio de 2019 